\title{
ENVELHECIMENTO DO CORPO: NOÇÕES DÍSPARES NAS MÍDIAS ATUAIS
}

\author{
Sonia Farber \\ Doutoranda em Teologia, pela Escola Superior de Teologia (EST), São Leopoldo-RS. Membro \\ da Rede Nacional de Tanatologia (RNT-Brasil). O presente trabalho foi realizado com o apoio da \\ Coordenação de Aperfeiçoamento de Pessoal de Nível Superior - CAPES. clafarber@uol.com.br
}

\begin{abstract}
RESUMO
O ser humano desenvolve-se passando por fases que se sucedem no ciclo da vida, a última delas é a velhice. Ao longo da história da humanidade o envelhecimento foi compreendido de modos diversos, conforme a sociedade e o tempo. Atualmente os meios de comunicação reforçam conceitos e estabelecem noções contraditórias sobre a velhice. Este artigo apresenta alguns limites na argumentação midiática e propostas para compreensão desta realidade vital.
\end{abstract}

\section{PALAVRAS-CHAVE}

Envelhecimento, mídia, morte.

\section{TeRMINOLOGIA, CONCEITOS E DEFINIÇÕES}

Emerge a necessidade de pesquisas multidisciplinares frente à complexidade das realidades evocadas pelo constante êxodo humano, em que cada avanço é alcançado com o término de uma condição de vida anterior. As ciências da comunicação são conclamadas a ajudar nesta tarefa, porém, confrontam-se com dificuldades importantes para retratar, e abordar, o envelhecimento humano, porque não existe linguagem unívoca, para todos os campos de conhecimentos e saberes, nem há consenso nas definições e conceitos para se referir ao processo do envelhecer e ao sujeito que envelhece.

Apesar disso, tornou-se corrente associar à expressão "terceira idade" a primeira fase do envelhecimento. O médico e gerontólogo Jean-Auguste Huet, no ano de 1956, pronunciando-se na assembleia municipal de Paris acerca dos direitos dos aposentados, referiu-se àqueles que faziam parte desta classe como sendo pessoas que vivem a sua terceira idade (troisième âge). Huet cunhou a expressão e esta passou a ser repetida (Debray, 1961), e utilizada amplamente, vinculando o envelhecimento com a aposentadoria, ainda que, possivelmente, o autor não tenha tido a intenção de reduzir o espectro de alcance de suas palavras, sendo, assim, temerário deslocar suas palavras do contexto em que foram pronunciadas (Lenoir, 1979). De modo especial, Huet dedicou-se à implementação de organismos e expedientes que visassem o bem estar, e o cuidado aos idosos, sendo sua a iniciativa de fundar a Sociedade Francesa de Gerontologia, no ano de 1961 (Lapierre, 1983).

O pós-guerra é, portanto, o contexto em que surge o conceito, ou quando é "inventada" a terceira idade, como sugere "L'invention du troisième âge" (Lenoir,1979) e, esta emerge em meio a debates acerca da responsabilidade social e a necessidade de políticas públicas que contemplem a situação vital das pessoas acima de 60 anos, que carecem de auxílio financeiro e cuja aposentadoria não cobre as necessidades reais da condição física própria desta faixa etária (Ruelle, 2003). Atualmente a 
Organização Mundial de Saúde considera que a pessoa está na terceira idade a partir dos 65 anos, para os habitantes de países desenvolvidos, e 60 para os que vivem em países subdesenvolvidos, a exemplo da África subsaariana (WHO, 2003). No Brasil, por definição, idosa é a pessoa com idade igual ou maior que 60 anos, segundo a Lei 8.842, capítulo I, Art. $2^{\circ}$, de 4 de janeiro de 1994 da Política Nacional do Idoso, e a Lei 10.741, Art. 1, de $1^{\circ}$ de outubro de 2003 do Estatuto do Idoso.

Convencionado que aos 60 anos as pessoas passam a estar na terceira idade, resta outra questão: qual o termo apropriado para identificar os sujeitos que atingem esta idade? É consenso que a palavra "velha (o)" é pejorativa, e a palavra "ancião(ã) na maioria das culturas não é utilizada; adulto maduro, sênior e maiores são termos difundidos entre os profissionais da geriatria e gerontologia, e aceitos pelas pessoas de terceira idade. Apesar disso, esta terminologia não é consenso e, com frequência, surgem neologismos e novas expressões na tentativa de propor linguagem mais inclusiva e de abarcar as realidades próprias desta faixa etária.

\footnotetext{
Hoje, os cientistas sociais que se especializam no estudo do envelhecimento se referem a três grupos de adultos mais velhos: os "idosos jovens", os "idosos velhos" e os "idosos mais velhos". Cronologicamente, o termo idosos jovens geralmente refere-se a pessoas de 65 a 74 anos, que costumam estar ativas, cheias de vida e vigorosas. Os idosos veIhos, de 75 a 84 anos, e os idosos mais velhos, de 85 ou mais anos, têm maior tendência para a fraqueza e para a enfermidade e podem ter dificuldade para desempenhar algumas atividades da vida diária. (Papalia, Olds \& Feldman, 2006)
}

Com o êxito da biotecnologia e das mudanças de estilo de vida, a longevidade é cada vez maior, em contrapartida, os idosos reivindicam novas abordagens e terminologias que minimizem a semântica e o campo associativo de fim da vida. A ideia da mortalidade e consciência da transitoriedade é reforçada pelas expressões que foram correntes até a poucas décadas ao se referir ao idoso. O desafio da comunicação contemporânea é encontrar formas e expressões que contemplem a realidade do idoso de modo inclusivo e sem se prestar a interpretações ambíguas

\section{Adulto MAduro: visões Plurais}

Sociedade é uma palavra que, com frequência, é utilizada para representar uma instituição diluída, que existe como que pairando sobre as realidades do cotidiano. Nesta concepção mítica, a sociedade possui características de "nave-mãe" com inteligência autônoma e manipuladora, que impõe e condiciona o agir dos que vivem sob sua égide. Este mito é facilitador das ideias e posicionamentos que os indivíduos nutrem, mas que remetem a uma instância fora de si, consequentemente, projetando a responsabilidade e o ônus para uma entidade que the exime de compromisso. Desta forma, as opções de vida são carregadas do imaginário coletivo de que não poderia ser de outra forma, pois a "sociedade" diz que é assim que deve ser.

Em se tratando de envelhecimento e, especialmente, das hermenêuticas atuais do envelhecimento, é necessário que se tenha clareza nos postulados e bomsenso nas práticas, para evitar que se emancipe de um padrão de preconceito e coloque outro em seu lugar. A passagem da mentalidade do velhinho dependente, 
passivo e à espera da morte para o cidadão ativo, autossuficiente e capaz deve, obrigatoriamente, ser uma visão sistêmica, levando em consideração as condições naturais do corpo e do ser em envelhecimento.

Por um lado, o ancião é visto como um entrave nas atividades e no fluxo cotidiano da sociedade e, não raro, relegado a uma condição de inexpressão familiar e invisibilidade social.

\begin{abstract}
Quando o sujeito começa a vivenciar a velhice, às vezes, alguns referenciais podem se perder, algumas referências que tiveram presentes em toda a sua vida e que demonstravam quem ele era e seu posicionamento social. Por exemplo: se esse sujeito tinha voz ativa nas decisões de sua família, hoje, velho, ele não é mais consultado, ele não faz mais parte fundamental do diálogo familiar. Esse momento pode ser bastante conturbado, pois o idoso se concebe como um desconhecido para si mesmo, já não localiza seu papel dentro dos ambientes sociais. Essa perda de referência, de autonomia, de posição ativa, se agrava quando a família e a sociedade não atribuem um papel social ativo ao idoso, considerando-o inútil, um peso social. (Stacheski \& Massi, 2011)
\end{abstract}

O ritmo acelerado da vida, em ambiente urbano, não conseguem absorver as necessidades de cuidado dos idosos e, nem mesmo a arquitetura e o espaço domiciliar são aptos para acolher adultos maduros dependentes. Esta realidade é confirmada pela existência, e criação, de novos espaços de recolhimento de idosos, asilos e casas de repouso.

Por outro lado, a estimativa de vida avançou e as pessoas que há 50 anos seriam tidas como anciãs, hoje são conhecidas como pessoas de terceira idade, e estão em busca de realizações e atividades sociais e acadêmicas, que não tiveram oportunidade de conquistar nas etapas anteriores da vida. Atualmente, a pessoa com mais de 65 anos é produtiva, inserida no mercado de trabalho e atuante na sociedade fazendo com que paradigmas sejam quebrados e uma nova noção de envelhecimento emerja.

Em 2008, foram realizados no Brasil 629.000 procedimentos estéticos, dos quais 71.000 foram feitos em pessoas de 51 a 64 anos, e $24.000 \mathrm{em}$ pessoas com mais de 65 anos (Soares, \& Cordeiro, 2009). Esta realidade tende a se firmar e crescer quantitativamente, na mesma medida em que a sociedade impõe padrões estéticos que, naturalmente, poucos corpos adequam-se, e com o envelhecimento, a tendência é perder, se já os possuiu.

As mídias, eventualmente, encorajam os idosos a não sê-lo. Ou, não podendo fugir desta realidade, no mínimo mascará-la. Emblemática é a propaganda publicitária na qual, idosos se transvestem de roqueiros e são aceitos socialmente, se desvestem de roqueiros e são ignorados. Nos meios de comunicação, na maioria das vezes, a inserção da pessoa idosa é desejável contanto que se adeque esteticamente. Exceção feita ao idoso cult presente na cultura local como o filósofo, o pensador que rompe com as convenções sociais e conquista o privilégio de poder ser velho, ter a aparência da idade que realmente tem. Este é um espírito livre, mas a poucos é feita esta concessão. No Brasil, personagem ilustre foi o "profeta Gentileza" que pregava, em praças e viadutos, um discurso apocalíptico e terno, cujo bordão era "gentileza gera gentileza, humanidade gera humanidade". Foi aceito e 
reverenciado, especialmente, após sua morte aos 79 anos (Veit, 2011).

Numa propaganda de cerveja é estabelecida a associação da ideia de consumir a bebida e remoçar e, neste caso, rejuvenescer seria a possibilidade da conquista da vida plena, resgate da erotização e reafirmação da identidade perdida. Sexualidade, erotização e genitalidade são requisitos impostos como atestação da vida que permanece; sendo desprovido destas prerrogativas o idoso é colocado à margem, na mídia em geral e em alguns grupos específicos. O acento da problemática recai na exigência social de afirmar a condição de aptidão para a vida sexual ativa. Paradoxalmente, estudos demonstram que a sexualidade do adulto maduro passa por transformações, mas não se extingue.

\footnotetext{
Há uma suposição convencional na cultura de desconsiderar os aspectos emocionais, principalmente a existência de desejo, nas gerações dos mais velhos, uma vez que uma das características para as mulheres, neste período, seria o encerramento do ciclo reprodutivo. Quanto aos homens, a falta de investimento do objetivo de procriar. Tal postura - de pensar a sexualidade a partir de uma concepção de que, biologicamente, ao término da procriação, ocorre um decréscimo da libido sexual - exige ser repensada, porque a pulsão sexual e de autoconservação - vida, quando desinvestida, cede lugar à pulsão de morte e esta silenciosamente mina o erotismo. (Kernberg apud Balbimotti, 2005)
}

A vida na ancianidade tem características próprias - como em cada uma das precedentes -, que serão mais ou menos prazerosas quanto for o produto da equação expectativa / frustração. Os procedimentos apresentados como rejuvenescedores nem sempre resultam no que prometem - e os meios de comunicação são pródigos em exemplos -, além do que, não são acessíveis a todos, causando um novo nicho de exclusão. Idoso que parece idoso passa a ser considerado descuidado ou, no mínimo, descapitalizado.

Enquanto a sociedade contemporânea requer que o ancião tenha vida ativa e físico forte capaz de proporcionar autonomia, Marco Túlio Cícero (séc. I a.C.), na obra "Saber envelhecer", apresenta que é perda de tempo e energia, além de ser totalmente improdutivo, lamentar-se pela etapa pregressa da vida. Desta forma, o idoso não deve lamentar-se pela juventude perdida, nem o adolescente pela infância, ou o jovem pela adolescência, mas, todos devem vivenciar o que de meIhor esta fase do ciclo vital lhes proporciona. Para Cícero, na velhice o importante é a sabedoria e o exercício intelectual, como demonstra na questão que levanta: "Conta-se que Mílon fez sua entrada no estádio de Olímpia carregando um boi sobre os ombros. O que vale mais? Ter este vigor físico ou aquele, inteiramente intelectual, de Pitágoras?" (Cícero, 2005).

Posto estes dois enfoques, uma nova reflexão emerge: Quem está interessado e visa ganhos com este novo conceito de velhice? Podemos não ter a resposta, ainda que sejam muitas as hipóteses, não individualmente, mas corporativas e institucionais.

Se a velhice com sua realidade estética, debilitação física progressiva, e comprometimento nos vários âmbitos da vida é obnubilado pelo ícone do jovem de cabelo branco, há que se refletir sobre as questões de fundo que subsidiam esta nova impostação. Em "A Reinvenção da Velhice" a autora propõe uma discussão acerca das imagens de velhice que estão sendo inculcadas atualmente. Diz ela: 
Pensar na visibilidade alcançada pela velhice é atentar para o duplo movimento que acompanha sua transformação em uma preocupação social. Assistimos, por um lado, a uma socialização progressiva da gestão da velhice; [...] Por outro lado, nesse movimento de socialização não está ausente o que venho chamando de processo de reprivatização, que transforma a velhice em uma responsabilidade individual -, e, nestes termos, ela poderia desaparecer de nosso leque de preocupações sociais. (Debert, 2004)

Seguindo este raciocínio os meios de comunicação tornam-se agentes reprodutores desta concepção de velhice, na qual o próprio ancião - posto que é autossuficiente, ágil, produtivo e capaz - deve responsabilizar-se pela sua vida, eximindo, assim, a microssociedade (família), a sociedade em que está inserido e a macrossociedade (todo gênero humano) da responsabilidade de comprometer-se com a vida e o cuidado aos idosos. Esta noção se configura em uma faca de dois gumes, que é mantida amolada pelos próprios anciãos, visto que exteriorizam o que nem sempre é de fato, e sedimenta a imagem de autonomia e desnecessidade de ajuda.

\section{ENVELHECIMENTO E QUESTÃO GÊNERO}

O processo de envelhecimento tem desdobramentos diferentes nos homens e nas mulheres, o que não significa que todas as pessoas do mesmo gênero enveIheçam da mesma forma e com a mesma sintomatologia, pois esta é condicionada não só pela idade, mas, pela cultura, ambiente e condições de vida.

As mulheres se percebem envelhecendo com o aparecimento dos sinais característicos da menopausa, enquanto que, os homens não têm sintomas tão nítidos das mudanças que estão se ocorrendo em seu corpo, pois, ainda estejam se processando, as transformações físicas nos homens são mais sutis. Apesar disso, o impacto das limitações e perdas advindas do envelhecimento é mais sentida nos homens; segundo uma teoria isto se registra por haver uma diferença significativa de incidência de mudanças ao longo da vida da mulher, comparando-se com a vida do homem. Basicamente, a mudança mais drástica no corpo masculino acontece na puberdade e depois disso há um hiato até iniciar o envelhecimento; diferentemente das mulheres que passam por sucessivas transformações físicas e, algumas delas, repetidas vezes, como no caso das gravidezes (Debert, 1994).

Outra diferença entre o envelhecimento feminino e masculino reside na longevidade. No Brasil, segundo relatório do Instituto Brasileiro de Geografia e Estatística - IBGE, as mulheres vivem, em média, oito anos mais que os homens. Se a expectativa de vida das mulheres é maior que a dos homens, em contrapartida, elas são acometidas por doenças crônicas em decorrência da idade (Balbinoti, 2005).

Diferenças entre o envelhecimento feminino e o envelhecimento masculino existem e são registradas, de modo especial, pelos profissionais da área da saúde dedicados à gerontologia e geriatria. Mas, no aspecto antropológico, há semelhanças importantes no envelhecimento independente do gênero.

Hoje o duplo padrão de envelhecimento está desaparecendo (Gullette, 1998); os homens também sofrem com a valorização dada à juventude. Isso se aplica particularmente ao mercado de trabalho e ao mundo dos negócios. Não é coincidência que tratamentos de combate ao envelhecimento para homens tenham dado um salto de crescimento em uma época de 
redução corporativa (Spindler, 1996). Os homens atualmente gastam tanto quanto as mulheres em produtos cosméticos (Gullette, 1998) e estão fazendo mais cirurgias estéticas (Papalia, Olds \& Feldman, 2006).

O ônus do envelhecimento é partilhado por ambos os sexos, nas sociedades de consumo e produtividade, que isolam e descartam o idoso, tornando-o produto e, não mais, sujeito da história, como afirma a autora do livro 'Demências':

\footnotetext{
Quando se privilegia a idéia de juventude e se expulsa o tema da morte para um lugar cada vez mais marginal ou banal as pessoas mais idosas são empurradas a abandonar o que parece ser uma lucidez insuportável, são obrigadas a reduzir ao mínimo, e até a anular drasticamente, todas as ligações com um meio especialmente hostil, são compelidas a não querer saber mais de um mundo do qual não podem participar, no qual já não tem mais lugar. (Goldfarb, 2004).
}

Nenhuma semelhança, porém, é tão marcadamente presente no envelhecimento de homens e mulheres quanto a noção da proximidade da morte. Se, sob um aspecto, a certeza de adentrar na última fase do ciclo vital faz emergir a consciência da finitude e mortalidade inviabilizando projetos em longo prazo, por outro lado o processo de envelhecimento pode suscitar novo ânimo de vida, fazendo com que envelhecer torne-se uma experiência produtiva e cheia de significado.

Nem todas as condições de vida, na terceira idade e velhice, são impostas pela sociedade ou condicionadas pela genética, envelhecer pode, também, ser um tempo de tomada de decisões livres e conscientes. Mulheres e homens ao adentrarem na velhice sentem-se mais livres para romper com situações e relacionamentos insatisfatórios; a consciência da brevidade da vida alavanca a urgência de posturas em favor do bem-estar e do fortalecimento do que é essencial e, neste aspecto, não há distinção de gênero.

\section{IMPORTÂNCIA DO CONFRONTO COM AS MORTES SIMBÓLICAS}

A apologia da imagem do velhinho caquético não contribui com a resolução do problema aqui proposto, tampouco a imagem nostálgica da vovó na cadeira de balanço assexuada, obesa e contadora de histórias pode ajudar. Facilita a aquisição de novo olhar sobre esta questão a paulatina aproximação com as situações que apontam para a provisoriedade da vida. Negar o envelhecimento é subtrair das reflexões a proximidade da última fase do ciclo vital e, depois dela, a morte.

$O$ enigma do evento morte e do ato de morrer acompanha a vida de todos os homens, mas, muitos, senão a maioria, fazem do curso de seus dias um constante agir com vistas a um futuro histórico, sem considerar a possibilidade de morrer. Essa reivindicação de viver para sempre e a consequente angústia diante da morte não são dissolvidas pela pesquisa acadêmica com instrumentos e categorias científicas. Não basta racionalmente afirmar que essa é uma contingência humana, orgânica, biológica e mesmo existencial para elucidar a questão, visto que a tragicidade da morte está vinculada à própria constituição antropológica: o ser humano é ordenado para a vida, e a morte nega essa que é sua destinação primordial. O ser humano está em constante construção e aprende com as experiências acumuladas ao longo da vida. $O$ paradoxo é que quanto mais vive, mais especializado e preparado para viver ele está 
e, na mesma proporção, mais se afasta da vida e vai de encontro à morte. Tal realidade pode ser desesperadora, consoante à significação que a pessoa der ao existir; a perda de sentido de vida leva à falta de sentido na morte. (Färber, 2009)

\begin{abstract}
O Séc. XX está marcado pela interdição e pelo silêncio em torno do tema da morte. De acordo com o autor, é a morte que se esconde e que é vergonhosa, o grande fracasso da humanidade. Há uma supressão da manifestação do luto, a sociedade condena a expressão e a vivência da dor, atribuindo-lhe uma qualidade de fraqueza. Há uma exigência de domínio e controle. A sociedade capitalista, centrada na produção, não suporta ver os sinais da morte. Os rituais do nosso tempo clamam pelo ocultamento e disfarce da morte, como se essa não existisse. (Corrêa, 2000)
\end{abstract}

Elaborar a morte real e objetiva requer do indivíduo exercício vigoroso e processual, por isso, lento. Porém, esse itinerário de significação da morte não necessita, obrigatoriamente, ser vivenciado a partir do evento, mas, de modo profilático, significando, conscientemente, as sucessivas perdas que acontecem ao longo da vida. Quando uma morte simbólica é assumida e vivenciada em sua inteireza, a pessoa adquire força para os embates que, certamente, terá no futuro. Por isso, é importante viver e não se esquivar dos processos de lutos simbólicos que se apresentam. Mitos exercem papel e função valiosa, como exercícios de processamento das mortes simbólicas e preparação para mortes objetivas, pois fortalecem a têmpera e a disposição interior e favorecem a aquisição do autoconhecimento, da real noção de seus limites emocionais e das necessidades de suporte de cada um. Munidos destes expedientes, as mortes simbólicas exercerão papel pedagógico e favorecerão o exercício de uma verdadeira educação para a morte.

Superar o tabu da morte não é tarefa fácil, nem rápido, exige novas estratégias para que este objetivo seja alcançado. Há que se educar para a morte partindo da premissa de que de todas as realidades possíveis de acontecer aos seres humanos, a morte é aquela que, indubitavelmente, atinge a todos, para que a educação seja completa e totalizante.

Abordar esse tema nem sempre é comum e, na maioria das culturas, não é fácil. O recurso adotado por muitos grupos é o uso da mitologia, no qual está presente a ideia da morte, ainda que apenas implicitamente. Mitos são necessários para a formação do imaginário humano, especialmente no que toca às questões de difícil argumentação e de alto nível de abstração. Os mitos, assim utilizados, não são construções mentais ou explanações bizarras e impossíveis, mas evocam situações nas quais pessoas comuns vivenciam experiências incomuns. O mito não responde a todas as perguntas nem fecha as questões, mas, ao contrário, abre a possibilidade de reflexão e de busca para encontrar respostas criativas para problemas e impasses do cotidiano humano. E nada está mais presente no cotidiano que a morte. Daí a importação da elaboração das mortes simbólicas para o enfrentamento da morte objetiva.

Culturalmente, a morte é celebrada de forma simbólica e mitológica, marcando a transição de uma fase da vida para outra. A utilização do recurso imagético visa amortizar as dificuldades de assimilação das mudanças e a insegurança causada pelo desconhecido. A passagem de uma realidade para outra é impactante, porém, não é irremediavelmente traumatizante, dependendo dos mecanismos de 
suporte emocional e psicológicos que forem empregados. Diferentes são as formas interpretativas de situações semelhantes, a saber, a falta de dentes no recémnascido, na fase da troca de dentição e na velhice, em que são marcados os status de nascimento, renovação e morte.

O cotidiano é marcado por mitos que evocam as várias mortes, na mesma vida; estes são celebrados por meio de ritos consagrados pelo grupo, e transmitidos sucessivamente de geração em geração.

No itinerário do desenvolvimento humano, a morte é parte integrante e, simultaneamente, ponto para o qual convergem todas as fases anteriores. Morrer é alcançar o pleno desenvolvimento da existência. Todo organismo vivo, morre. Mas, só o ser humano pode refletir sobre essa dimensão da vida. Apesar de a vida estar ordenada para a morte e o ser humano estar aparelhado para racionalizar, entender e significá-la, culturalmente a morte foi banida das elucubrações e afastada até do pensamento, ainda que nem sempre e nem em todos os lugares tenha sido assim.

Para o homem ocidental moderno, a morte passou a ser sinônimo de fracasso, impotência e vergonha. Tenta-se vencê-la a qualquer custo e, quando tal êxito não é atingido, ela é escondida e negada. (Combinato \& Queiroz, 2006)

Com a negação da morte, não apenas o assunto é omitido nas conversas, mas sua ocorrência banida da visão social, ou quando isto não é possível, a morte é disfarçada e maquiada. A dificuldade em aceitar a morte como fenômeno integrante da vida é decorrente da ausência de reflexão séria e progressiva que possa dar suporte para que ela seja enfrentada diretamente e sem máscaras. Enquanto a reflexão avança paulatinamente, mas em ritmo desacelerado, na esfera acadêmica e científica, a morte cotidianamente marca a vida em sociedade. É o ciclo que se mantém e se refaz no desenvolvimento do ser individualmente e da humanidade como espécie. Este ciclo é ordenado pela própria constituição humana, que pode ser alterado, adiado ou negado, mas jamais interrompido. O processo de desenvolvimento humano deflagrado com a geração da vida percorre várias fases de duração, que podem ser culturalmente assinaladas. Algumas são evidentes, outras são processuais e de índole subjetivas, mas todas acontecem sob o signo da transitoriedade da vida, que alcança seu zênite com a morte.

\section{Conclusão}

Terceira idade tornou-se eufemismo para velhice, mas, esta expressão vem sendo amenizada pela designação coloquial "melhor idade", pois a sociedade percebe o descompasso entre as convenções acerca do estado do envelhecimento e as condições reais em que se encontram os idosos, que estão superiores à noção tida até pouco tempo.

Os 65 anos são o ponto de entrada tradicional na terceira idade, a última fase da vida. Contudo, muitos adultos aos 65 - ou até aos 75 ou 85 - não se sentem nem agem como "velhos". As diferenças individuais tornamse mais acentuadas nos anos avançados, e o "use ou perca" torna-se uma regra urgente. A maioria dos adultos mais velhos possui boa saúde física e mental; as pessoas que se mantêm física e intelectualmente 
ativas podem manter-se firmes na maioria dos aspectos e até aumentar de competência. O funcionamento físico e o cognitivo possuem efeitos psicossociais, os quais, muitas vezes, determinam o estado emocional de uma pessoa e se ela pode viver de maneira independente. (Papalia, Olds \& Feldman, 2006)

É importante ressaltar que envelhecimento acontece em sequências e como consequência do processo vital deflagrado com o nascimento. Sendo o ser humano um complexo bio-psíquico-social o envelhecimento envolve, também, estes três aspectos da vida humana, que entendo como o tripé do envelhecimento. As demandas referentes a cada um destes três setores da vida do idoso devem ser contempladas, tendo em vista a especificidade de cada um. A complexidade deste processo será tanto melhor compreendida quanto maior for o esforço por desintrincar o que é próprio de cada um dos âmbitos da vida do ser que envelhece.

Evidentes são as informações oriundas do relógio biológico sobre a pessoa em envelhecimento, pois o próprio corpo emite sinais de desgaste decorrente dos anos vividos, manifestando um processo natural (Papalia, Olds \& Feldman 2006). Porém, na velhice evidenciam-se limitações e doenças que, eventualmente, são interpretadas como inerentes ao envelhecimento, o que nem sempre se verifica. Quadros sistêmicos e agudos de patologias que comprometem a qualidade de vida na velhice, muitas vezes, são decorrência do estilo de vida nas fases anteriores, não significando, portanto, que envelhecimento seja sinônimo de dor e sofrimento.

Em contrapartida, o relógio psíquico segue outra premissa, e esta é regulada pelo mecanismo individual de compreensão da vida, resiliência ante as mudanças e impactos sofridos, elaboração dos lutos simbólicos e frustrações, sendo estes dispositivos que darão ao idoso a informação subjetiva sobre o estado de seu envelhecimento. A pertinência do estatuto do relógio psíquico reside nos múltiplos depoimentos dados pelos próprios sujeitos do envelhecimento, que se dizem estranhos e em conflito por entenderem-se jovens psiquicamente estando em corpos com sinais de velhice.

A terceira instância que indica o envelhecimento é o relógio social (Bee, 1997); e este influencia e é influenciado pela mídia que, como um termômetro coletivo, demonstra a visão da sociedade a respeito do idoso e do envelhecimento. A idade social é culturalmente definida e determinada pela forma como a sociedade entende o idoso e qual o papel que lhe compete. Atualmente, porém, as distinções culturais estão cada vez mais fracas e o acervo de tradições se dilui sob o impacto da globalização, na qual a uniformidade dos costumes e a impostação de formas transitórias de relacionamentos dão a feição "líquida" da sociedade pós-moderna (Bauman, 2005); e, nesta nova sociedade, o idoso busca firmar sua pertença grupal e atuação colaborativa.

O desejo de viver para sempre e a busca pela eterna juventude está presente nas sociedades de todos os tempos e lugares, mas é reforçada atualmente pelo espectro de produtos e técnicas produzidas e pela apresentação que a mídia faz deles. Tomemos por exemplo a expressão "anti-idade": nome e marca fantasia de cosméticos que passam a ideia de voltar, ou ao menos, parar o tempo. Se há quem venda a ilusão, há quem compre. Mas, de ambos os lados deve haver consciência de que está se tratando do tempo aparente, não do tempo real que, como no mito de Cronos (tempo), irremediavelmente, devora seus filhos. A mídia veicula não 
apenas marcas e produtos, mas conceitos, cosmovisões e noções de mundo e ser humano, por isso quando a argumentação midiática envolve a questão do envelhecimento, eventualmente, noções díspares se evidenciam.

Presta um desserviço social a mídia que propala aos idosos ideais irrealizáveis mantendo-os em estado de alienação, não favorecendo a conscientização de suas reais possibilidades de conquistas, prazeres e condição de vida com qualidade.

O importante contributo que a mídia, e os meios de comunicação em geral, prestam à reflexão gerontológica é o de evidenciar o papel do idoso naquilo que realmente é próprio da sua idade e condição, indicando as lacunas as serem preenchidas em vista do fortalecimento de uma sociedade igualitária.

\section{REFERÊNCIAS}

Balbinotti, H. (2005) Ser Adulto Maduro Hoje. Uma visão psicológica, Porto Alegre: Conceito.

Bauman, Z. (2005) Identidade, Rio de Janeiro: Zahar.

Bee, H. (1997) O Ciclo Vital, Porto Alegre: Artmed.

Cícero. (2005) Saber Envelhecer, Porto Alegre: L\&PM, 29.

Combinato, D., \& Queiroz, S. (2006) 'Morte: uma Visão Psicossocial', Estudos de Psicologia, Natal, Print Version, 11:210.

Corrêa, M. (2000) 'Morte Simbólica, não-ser em Vida: Construindo o Conceito', in III Conferência de pesquisa sócio-cultural. Campinas: UNICAMP, 4.

Debert, G. (2004) A Reinvenção da Velhice, São Paulo: Edusp.

Debert, G. 'Envelhecimento e gênero' (1994), Estudos Feministas, 2, 3: 33-51, Florianópolis: UFSC.

Debray, M (1961). 'Débats Parlementaires', in Journal Officiel de la République Française, 11: 593. Disponível em http://archives.assemblee-nationale.fr/1/cri/1960-1961-droit/003.pdf. Acesso em 13. fev. 2012.

Färber, S. (2009) Morte na Teologia e na Literatura, Porto Alegre: Pallotti.

Goldfarb, D. (2004) Demências, São Paulo: Casa do Psicólogo.

Lapierre, N. (1983) 'Guérir de vieillesse', Communications, 37: 149-165. Disponível em: <http:// www.persee.fr/web/revues/home/prescript/article/comm_0588-8018_1983_num_37_1_1558>. Acesso em 20. fev. 2012.

Lenoir, Rémi (1979) 'L'invention du Troisième Âge', Actes de la Recherche en Sciences sociales 26: 57-82. Disponível em: <http://www.persee.fr/web/revues/home/prescript-/article/ arss_03355322_1979_num_26_1_2630>. Acesso em 22. fev. 2012.

Papalia, D., Olds, S. \& Feldman, R. (2006) Desenvolvimento Humano. Porto Alegre: Artmed.

Ruelle, Pascal (2003) 'Prendre la Perspective de la Mort comme Appui de la Démarche d'Accompagnement de la Dernière Étape de la Vie en EHPAD', Mémoire de l'Ecole Nationale de la Santé Publique, Rennes, Bretagne. Disponível em: http://fulltext.bdsp.ehesp.fr/Ensp/ Memoires/2003/cafdes/ruelle.pdf. Acesso em 15. fev. 2012. 
Soares, M. \& Cordeiro, E. (2009) 'Aumenta a Procura por Cirurgia Plástica na Terceira Idade'. Disponível em <http://participedftv.globo.com/jornalismo/dftv/o,,mul1318030-10041,00-idos os+estao+cada+vez+mais+adeptos+a+cirurgias+plasticas.html>. Acesso em 26. fev. 2012.

Stacheski, D. \& Massi, G. (2011) 'Índices Sociais de Valor: Mass Media, Linguagem e Envelhecimento', Interface - Comunicação, Saúde, Educação, 37: 426.

Veit, C. (2011) 'O Profeta Gentileza'Rainha dos Apóstolos, 88: 38-39.

WHO. World Health Organization. Definition of an older or elderly person, (2003). Disponível em: <http://www.who.int/healthinfo/survey/ageingdefnolder/en/>. Acesso em 15. fev. 2012. 